\title{
Interface Discharge Behaviour at Polypropylene Nanocomposites and Silicone Rubber under AC Voltage
}

\author{
Jin-shan YU*, Chun-yan HAO, Jun-ke GUO, Xin HE and Xiang-ying YU \\ Tianjin Electric Power Research Institute, \\ State Grid, Tianjin, China \\ Email: hmgaoyu@126.com
}

\begin{abstract}
Polypropylene has a great electrical property and may be used as primary insulating material in electrical power cable. In cable accessory, the field distribution is often distorted since the very complicated physical structure, which makes interface discharge between $P P$ and cable joint insulation easy to happen. Polymer based nanocomposites has recently received a lot of attentions, which can offer a better insulation property than the neat polymer. In order to improve the electrical property of the PP/SiR interface, nano-sized MgO filler has been adding into PP matrix to form the socalled PP/MgO nanocomposites. The interface discharge behavior between the nanocomposites and the SiR have been studied. Obtained results showed that with the increase in the nano-particle content from $0 \mathrm{wt} \%$ to $5 \mathrm{wt} \%$, the interface breakdown strength firstly increases but then decreases. A proper content of $3 \mathrm{wt} \%$ nano-sized $\mathrm{MgO}$ adding can improve the interface breakdown strength by a fact of 3.5 . It is suggested that the interface breakdown strength can be enhanced through the adding of nano-sized MgO.
\end{abstract}

Keywords- Polypropylene; Nanocomposites; Silicone Rubber; Interface Discharge

\section{INTRODUCTION}

Cable accessory is an important part of a cable system, which is also the weakest point along a cable route. In recent years, power cables have been widely used thanks to its advantages of less land occupation, high reliability and low electromagnetic radiation. They have been an indispensable part of modern power system. It has been demonstrated in numerous articles that interface discharge along cable accessory tends to occur because of its strong distortion of electric field, which leads to the breakdown of interface and thereby inducing insulation failure to the cable system [1]. Consequently, with the purpose of operating the cable safely, it is of great necessity to investigate the interface discharge behavior within a cable joint or a cable terminal.

Over the years, a lot of contributions have been published to clarify the electrical insulation performance within the cable accessory, for instance, it was reported that with the increase of interfacial smoothness, the discharge voltage was increased [2]. It was also revealed that with the increase of the interface pressure, partial discharge could be strengthened [3]. Majid et al. proposed a theory on electric field distribution along the interface and the method of breakdown strength calculation, arguing that the interfacial breakdown strength is governed by the discharge inception stress of the air-filled cavities [4].

Nowadays, with the development of PP insulated power cable, the insulation property at $\mathrm{PP} / \mathrm{SiR}$ interface has drawn a lot of attentions $[5,6]$. It has been generally accepted that the interface discharge is still a drawback for the cable joint. Polymer based nanocomposites has received a plenty of sights from researchers as the electrical property of polymer material could be improved by the adding of nano-sized inorganic particles. In this paper, $\mathrm{PP} / \mathrm{MgO}$ nanocomposites have been prepared to test the effect of nano-filler adding on interface discharge performance at $\mathrm{PP} / \mathrm{MgO}$ and $\mathrm{SiR}$. Obtained results showed that the interface breakdown strength can be promoted if proper content of nano-filler is added into the neat PP. This information is helpful for the development of new material for cable application.

\section{EXPERIMENTAL SETUP}

\section{A. Sample Preparation and Electrode Arrangement}

The $\mathrm{PP} / \mathrm{MgO}$ nanocomposites was prepared by thermal press method. By adding $50 \mathrm{~nm} \mathrm{MgO}$ particle into Isotactic PP (PPH-T03) (Sinopec Beihai company, China) with weight content of $1 \mathrm{wt} \%, 3 \mathrm{wt} \%$ and $5 \mathrm{wt} \%$, the nanocomposites were therefore made as test samples. As regards to the Sillicone Rubber sample, high temperature vulcanized silicone rubber (110) (Ximei Silicone Materials, China) were employed. The length and width of the samples were $8 \mathrm{~cm}$ and $5 \mathrm{~cm}$, while the thickness was $5 \mathrm{~mm}$. As shown in Fig. 1, a pair of point to plane electrode system was used for electrode configuration. The PP nanocomposites and $\mathrm{SiR}$ samples were kept at a physical pressure of 0.12 $\mathrm{MPa}$. The electrodes were formed by attaching $55 \mu \mathrm{m}$-thick aluminum foil on the surface of $\mathrm{PP} / \mathrm{MgO}$. The point electrode was featured with an angle of $30^{\circ}$. The interval between the point and the plane electrode was $4 \mathrm{~mm}$. 


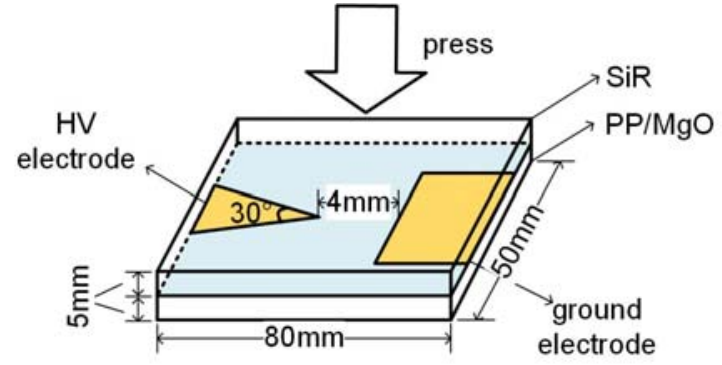

Fig. 1. Schematic diagram of the sample position and the electrode arrangement.

\section{B. Test Circuit and Procedure}

The test circuit is shown in Fig. 2. A high frequency current transformer (HFCT) was used to measure the discharge current and a high speed AD convertor was used to collect the data. A charge-coupled device (CCD) camera was used to monitor the propagation of interface discharge channel. Before the test, the sample surface was cleaned with ethyl alcohol and was dried at $40^{\circ} \mathrm{C}$ for 1 hours. The experiment was conducted at room temperature with relative humidity of $45 \%$. By applying AC voltage with $20 \mathrm{kVrms}$ of $50 \mathrm{~Hz}$ between the electrodes, surface discharge was initiated and the discharge current was measured until the insulation interval was breakdown. The PRPD features during the discharge propagation process were extracted and the statistics of discharge magnitude were obtained.

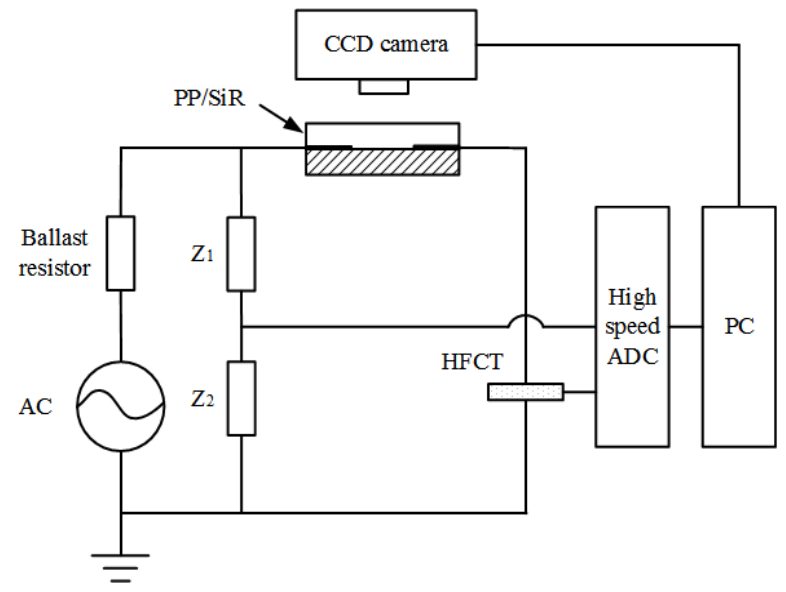

Fig.2. Schematic diagram of the test circuit.

\section{RESULTS AND DISCUSSION}

A group of typical interface discharge behavior is shown in Fig. 3 by taking the neat $\mathrm{PP}$ and $\mathrm{SiR}$ as an example. Interface discharge will happen when the high frequency $\mathrm{AC}$ voltage was applied between the point to plane electrode. It was found that the average time for the interface breakdown of untreated $\mathrm{PP} / \mathrm{SiR}$ was about $40 \mathrm{~s}$, during such a time period three stages could be found, i.e. (a) discharge initiation, (b) discharge channel propagation and (c) breakdown. The characteristics of the three stages monitored through the CCD camera is shown in Fig.3. Normally, in the stage (a), the discharge pulses are sparse and relatively low. After that, the discharge magnitude and discharge repetition rate increase in stage (b) compared with the former stage (a). Stage (a) lasts for a relatively short time with a typical period of $\sim 15 \mathrm{~s}$, and stage (b) has a time of about $20 \mathrm{~s}$ in general. As regards to the stage (c), the breakdown happens between the electrodes that a discharge arc appears with remarkable light emission and heat, the insulation interval is therefore short-circuited with the permanent loss of insulation property of the interface. Some other features that need to be noticed are those at stage (a) no obvious discharge phenomena could be observed.
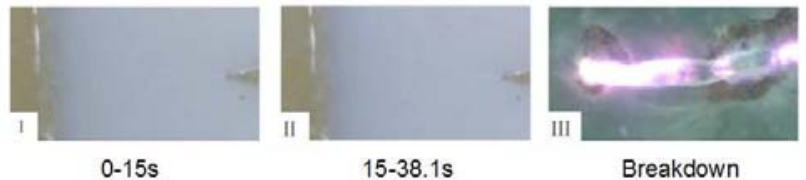

Fig. 3. An example of interface discharge at PP and SiR.

Fig. 4 show the effect of nano-filler contenct on the time to breakdown for both neat $\mathrm{PP}$ and $\mathrm{PP} / \mathrm{MgO}$ nanocomposites. It can be observed that the time to breakdown is about $40 \mathrm{~s}$ with neat PP. With the increase of the nano-filler content from $0 \mathrm{wt} \%$ to $3 \mathrm{wt} \%$, the time grows to about $140 \mathrm{~s}$, which means that the breakdown strength is improved by a factor of 3.5. However, a further increase in the nano-filler content induces a decrease in the breakdown time which infers that the dielectric strength at the interface is reduced. It has been claimed in our early research that interface discharge between the PP and $\mathrm{SiR}$ is related to the surface trap distribution as well as surface roughness. At the intial stage, the discharge is associated with surface trap depth. Deep surface trap results in a difficult initiatioin of the discharge. At the propagation stage, the discharge is dependent primarily upon the surface roughness, large roughness leads to fast propagation of discharge channel and thereby accelerating the breakdown phenomena. In order to explain the test results shown in Fig. 5, surface roughness of the test samples have been measred by using a mechanical surface roughness measurement equiment, and the results are shown in Fig. 6.

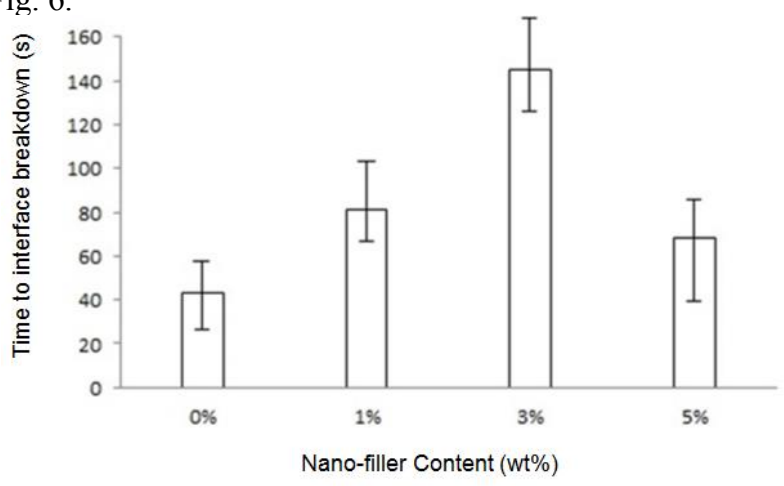

Fig. 4. Relation between the time to breakdown and the nano-filler content. 
It can be obtained in Fig. 5 that with the growth of the nano-filler content the average roughness of the nanocomposites initially decreases then appears to increase. The roughness of the neat $\mathrm{PP}$ is about $160 \mathrm{~nm}$, but with a 3 $\mathrm{wt} \% \mathrm{MgO}$ particle adding the composites holds an average roughness of about $70 \mathrm{~nm}$, which is much smaller that the neat one. A further increase in the nano-particle adding will contributes to an increase in the average roughness, finally to about $90 \mathrm{~nm}$ with $5 \mathrm{wt} \% \mathrm{MgO}$ adding. It is then argued that the variation in the time to breakdown should be attributed to the change in average roughness caused by the adding of $\mathrm{MgO}$ particles.

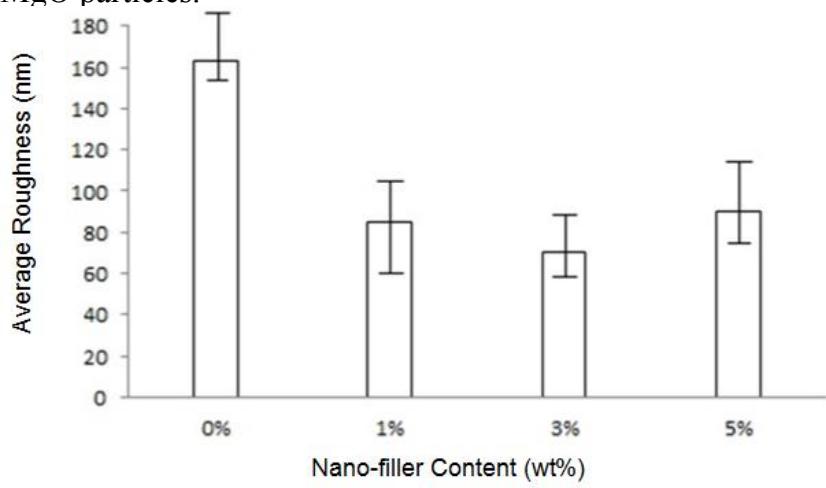

Fig. 5. Relation between the average roughness and the nano-filler content

\section{CONCLUSIONS}

This work focuses on the influence of nano-particle adding on the interface discharge beahviour between PP and $\mathrm{SiR}$. The main conclusions are summarized as follows,
1. With the increase of the nano-filler content from 0 $\mathrm{wt} \%$ to $3 \mathrm{wt} \%$, the time to breakdown increase from $40 \mathrm{~s}$ to $140 \mathrm{~s}$. With a further increase in the nano-filler content from $3 \mathrm{wt} \%$ to $5 \mathrm{wt} \%$, the time decreases from $140 \mathrm{~s}$ to $70 \mathrm{~s}$.

2. With the growth of the nano-filler content from 0 $w t \%$ to $5 \mathrm{wt} \%$, the average roughness of the sample decreases initially then tends to increase.

Our test results indicate that with the adding of proper content of nano-filler, the interface dielectric property between PP and SiR can be improved. Such a finding is helpful for the development of materials for cable insulation.

\section{REFERENCES}

[1] T. Christen, L. Donzel, and F. Greuter. "Nonlinear resistive electric field grading part 1: Theory and simulation,” IEEE Electr. Insul. Mag., vol. 26, no. 6, pp. 47-59, November 2011

[2] B. X. Du, X. H. Zhu, L. Gu and H. J. Liu. "Effect of surface smoothness on tracking mechanism in XLPE-Si-rubber interfaces," IEEE Trans. Dielectr. Electr. Insul., vol. 18, no. 1, pp. 176-181, February 2011

[3] L. Zou, Y. Tu, Y. P. Meng, et al. "Effects of interface pressure and surface roughness on the partial discharge between polyethylene and silicone rubber,” Insul. Mater., vol. 47, no. 3, pp. 94-102, 2014

[4] H. Majid and E. Ildstad. "Application of contact analysis on evaluation of breakdown strength and PD inception field strength of solid-solid interfaces," IEEE Trans. Dielectr. Electr. Insul., vol. 19, no. 1, pp. 1-7, February 2012.

[5] Y. Zhou, J. L. He, J.Hu, et al. "Evaluation of polypropylene polyolefin elastomer blends for potential recyclable HVDC cable insulation applications," IEEE Trans. Dielectr. Electr. Insul., vol. 22, no. 2, pp. 673-681, April 2015.

[6] C. D. Green, A. S. Vaughan, G. C. Stevens, et al. "On the temperature dependence of electrical and mechanical properties of recyclable cable insulation materials based upon polyethylene blends," IEEE Conf. on Electrical Insulation Dielectric Phenomena (CEIDP), Cancun, Mexico, pp. 36-39, October 2011. 